\title{
Una aproximación al tema del engaño en algunas comedias de Lope de Vega
}

\section{An Approach to the Topic of Cheating in some Comedies by Lope de Vega}

\author{
Juan Antonio Martínez Berbel \\ Universidad de La Rioja \\ ESPAÑA \\ juan.berbel@unirioja.es \\ [Hipogrifo, (issn: 2328-1308), 3.1, 2015, pp. 35-53] \\ Recibido: 04-02-2015 / Aceptado: 14-04-2015 \\ DOI: http://dx.doi.org/10.13035/H.2015.03.01.04
}

Resumen. Este trabajo ofrece una panorámica de los diferentes mecanismos del engaño en las comedias de Lope de vega. La tipología de estos engaños es asimismo revisada y aplicada a varias comedias lopescas.

Palabras clave. Teatro, Siglo de Oro, Literatura, Mentiras, Engaños.

Abstract. This paper gives an overview of the different mechanisms of deception in the plays of Lope de Vega. The typology of these delusions is reviewed and then applied to several Lope de Vega's plays.

Keywords. Theater, Golden Age, Literature, Deception, Cheating, Delusion.

Podríamos comenzar este trabajo con una suerte de juego muy cercano al silogismo. Que el enredo es básico en el teatro áureo es algo que todos fácilmente aceptaríamos. Que en el enredo es básico el engaño, quizá, también sea una aseveración que podríamos hacer nuestra. De lo cual podríamos inferir que el teatro tiene como un componente básico el engaño. A pesar de lo manipulado de la argumentación, supongo que se puede convenir de manera general que esta cuestión, la mentira, la ocultación, los fingimientos, son tan habituales en nuestro teatro áureo, especialmente en las comedias y, cómo no, en el teatro breve, que quizá la labor difícil no está en rastrear este tipo de elementos en los dramas, sino, todo lo contrario, intentar encontrar obras en las que no se den. Más que rastrear la pre- 
sencia de estos motivos la cuestión fundamental es responder a las razones de dicha presencia.

Situaba el tema en estos términos Delia Gavela en un trabajo reciente cuando afirmaba que

Lope se dio cuenta muy pronto de la eficacia de este recurso, que, como otras versiones del engaño, va intrínsecamente ligado al juego teatral, al hacer al público partícipe de cierta información desconocida por todos o por parte de los personajes, al implicar un alto grado de metateatralidad mediante travestismos literales, profesionales, sociales, etc. y al asentarse en el tan apreciado tópico barroco del engaño a los ojos?

Delia Gavela, si bien refiriéndose a un tipo de engaño específico, el del fingimiento de identidades, identifica a mi juicio tres elementos fundamentales para el uso general del engaño en el teatro aurisecular: la ligazón con el hecho teatral mismo, su relación con el propio juego escénico, la metatrealidad de este tipo de recurso y su imbricación en el propio carácter de lo barroco, a través de uno de sus tópicos más fructíferos. La presencia extensa e intensa de numerosísimos mecanismos que tienen que ver con el engaño, con la mentira, con la simulación en el teatro áureo, implica y demuestra, y a ejemplificarlo dedicaré las siguientes páginas, no ya lo rentable del recurso en sí, sino su carácter medular dentro de este teatro.

La importancia y penetración de los diferentes mecanismos del engaño y la mentira en nuestro teatro han recibido no poca atención por parte de la crítica especializada. La bibliografía dedicada al tema es extensa. No es objeto de este trabajo ser exhaustivo en su recopilación, pero creo que dibujan el marco conceptual del presente trabajo los de Arellano, Oleza, Carrascón, Hermenegildo, García Lorenzo, López Martínez, Oliva y Roso Díaz².

El presente estudio se estructurará en dos partes diferenciadas: por un lado me referiré a menciones explícitas a la mentira en algunas comedias. Podríamos decir que se trata de engaños menores, que forman parte del desarrollo de la trama, sin afectar decisivamente a la misma, pero que, a mi juicio, permiten emitir interesantes opiniones del autor o del público al que va dirigido. En muchos casos son lugares comunes, o prejuicios extendidos, pero, sea como fuere, ayudan a comprender el contexto general en el que se escribe nuestro teatro. En la segunda parte me centraré en lo que podríamos llamar, engaños mayores, aquellos en los que descansa el conflicto de una comedia, su planteamiento y, especialmente, su resolución, las intenciones profundas. Se trata de engaños que forman parte central e insustituible de las comedias en las que se insertan y que a menudo están presentes durante gran parte de la obra.

Las primeras apariciones a que me refería, aquellas puntuales pero que, a mi juicio, reflejan de manera particular lugares comunes, asunciones generales $y$, en

1. Gavela, 2011, p. 218.

2. Arellano 1999; Oleza, 1986, 1994 y 2001; Carrascón, 1997; García Lorenzo, 1989; Hermenegildo, 1995; López Martínez, 2014; Oliva, 2006; Roso Díaz, 2000 y 2007. 
definitiva, pulsan de alguna manera el carácter de la sociedad de la España de la época, se podrían expresar a modo de axiomas, de frases hechas o de generalizaciones, imperfectas quizá, pero que existen gracias a la presencia de una verdad compartida. El primero de ellos podría ser que «en la corte todo es mentira» o que «la corte es un mentidero». Un lugar común que no es exclusivo de la España barroca. De manera implícita aparece en numerosas comedias. Acercarse a la corte puede ser promesa de premios, pero peligro también de escarmientos a la ambición. No son pocas las comedias donde el protagonista se acerca a la corte para conseguir una mejora social y, bien resulta escarmentado, bien aprende pronto que las ventajas que proporciona la corte han de ganarse con métodos poco éticos. Un ejemplo lo tenemos en ¿De cuándo acá nos vino?, a la que me referiré más despacio más adelante, en la que Madrid es el escenario de un engaño continuado por parte de su protagonista. De índole diversa, pero descansando en el mismo axioma, podemos interpretar las reticencias de Juan Labrador en El villano en su rincón. En El laberinto de Creta, por recalar en un ejemplo explícito, Ariadna es abandonada por Teseo en una isla y vive como pastora. Oranteo, un príncipe se acerca a la isla y le ofrece llevarla a su reino.

ORANTEO ¿Quieres venir conmigo?

ARIADNA

No dejara

la simple vida de los campos verdes

por las mentiras de la corte vuestra

si me hiciérades príncipe de Lesbos.

ORANTEO Pues ¿no es mejor vivir con tal regalo?

ARIADNA Donde hay tantas pensiones, todo es malo;

mejor se alcanza aquí del árbol mismo

la fruta sazonada, que del plato;

mejor se bebe con la mano propia,

que en el cristal de la dorada taza;

aquí, sin los dineros, una plaza

común a todos, dió naturaleza ${ }^{3}$.

Habla de Lesbos, bien es cierto, pero no es difícil adivinar Madrid entre líneas.

Hay otro comentario extendido que sustentan no pocas apariciones puntuales en las comedias, como es el de que «la mujer es engañosa por naturaleza». No hace falta incidir en el enorme rendimiento que tiene esta idea en nuestro teatro. Todas las mujeres son mentirosas, por supuesto, pero de tanto en tanto surge una que se convierte en arquetipo, como la protagonista de El anzuelo de Fenisa.

No de otra suerte que la sombra huye

al resplandor del sol o la mentira

cuando se prueba la verdad gloriosa,

huyó Fenisa, que era amor fingido

a la luz del retrato de Dinarda,

3. Lope de Vega, El laberinto de Creta, vv. 2057-2068. 
y quedastes, Albano, de su engaño libre; piedad que le debéis al cielo, porque desde el primero movimiento de sus divinos tornos hasta el último que han dado sus esferas celestiales, no se ha visto mujer tan engañosa ${ }^{4}$.

Ella misma juega con esa idea y no le duelen prendas en declarar lo que considera una virtud, en varias citas distribuidas a lo largo de la comedia.

(Confío

que lo que buscaba hallé.

No ha venido forastero

a Sicilia en muchos años, mercader o caballero,

donde puedan mis engaños

pescar tan lindo dinero.

Una nave trae cargada

de paños, medias, y rasos) $)^{5}$.

Por supuesto, la mentira se convierte en una más de las virtudes con las que la naturaleza engalanó a las mujeres, a juicio de Fineo, criado de Teseo, en El laberinto de Creta, al conocer del alumbramiento monstruoso de Pasífae, esposa del rey Minos:

FINEO $\quad$ ¡Que nazca de una mujer
un monstruo como esta fiera!
mas, ¿de quién nacer pudiera
sino de su mismo ser?
Que no es menos de admirar
que nazca dellas la ira,
la lisonja, la mentira,
y el monstro de hacer pesar.
Que no le hay que más extrañe
naturaleza ipor Dios!
que el ver que la sirvan dos
y que a los dos los engañe ${ }^{6}$.

Otro «mentiroso por antonomasia es el vulgo», por acrítico, y por su inconsciencia a la hora de difundir rumores y favorecer la difamación. En El castigo sin venganza:

DUQUE Quien escucha, oye su daño, y fueron, aunque los dores, filósofos majaderos, 


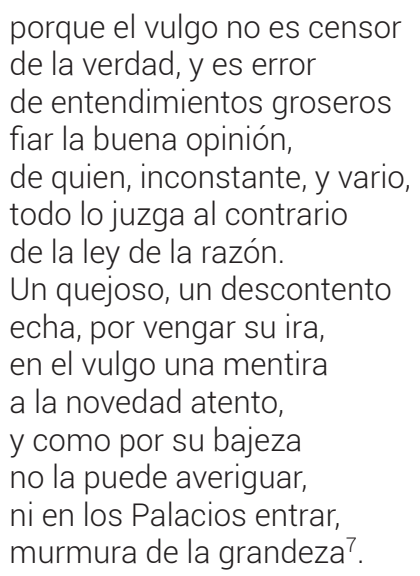

Más por su carácter anecdótico que por su representatividad traigo un ejemplo particular, el que alude al «engaño de la burocracia», del lenguaje administrativo y de sus documentos. Lo podemos observar en Las cuentas del Gran Capitán, cuando éste conversa con García de Paredes en los siguientes términos:

\begin{tabular}{|c|c|}
\hline CAPITÁN & $\begin{array}{l}\qquad \text { En verdad, que yo enviaba } \\
\text { buen Embajador en vos. } \\
\text { ¿No hay cartas? }\end{array}$ \\
\hline GARCÍA & $\begin{array}{l}\text { No traigo cartas, } \\
\text { porque todas son lisonjas } \\
\text { y mentiras disfrazadas. } \\
\text { Y basta, que os diga yo } \\
\text { lo que he visto, y lo que pasa } \\
\text { que no he mentido en mi vida, } \\
\text { ni he faltado a mi palabra, } \\
\text { ni dicho, que Dios os guarde, } \\
\text { deseando, que se caiga } \\
\text { este muro sobre vos, } \\
\text { como los que firman cartas. } \\
\text { Y he reparado, señor, } \\
\text { que todas son firmas falsas; } \\
\text { que si escriben una cosa, } \\
\text { y otra tienen en el alma; } \\
\text { si no cumplen lo que dicen, } \\
\text { y en cuanto dicen engañan, } \\
\text { no son firmas verdaderas }{ }^{8} \text {. }\end{array}$ \\
\hline
\end{tabular}

No podía Lope dejar de mirarse a sí mismo con el desparpajo que acostumbraba para poner en solfa incluso, o especialmente, la credibilidad de los poetas. En El 
marido más firme, Fabio, criado de Orfeo, prepara la mochila que le acompañará en su viaje al infierno; «los poetas también son mentirosos».

\begin{tabular}{|c|c|}
\hline FABIO & $\begin{array}{l}\text { Al infierno } \\
\text { llevo despachos, algunos } \\
\text { de amigos tan importunos, } \\
\text { que hasta con su fuego eterno } \\
\text { pretenden corresponderse. }\end{array}$ \\
\hline FÍLIDA & ¡Que gentil correspondencia! \\
\hline FABIO & $\begin{array}{l}\text { Aunque es agora en ausencia, } \\
\text { quien duda que esperan verse. } \\
\text { A ciertas bellas Cleopatras } \\
\text { llevo papeles, ¿que piensas? } \\
\text { y entre cuentas de despensas } \\
\text { escrituras de mohatras. } \\
\text { Otras supuestas me han dado } \\
\text { con antedatas crueles, } \\
\text { y también llevo papeles } \\
\text { de los que piden prestado. } \\
\text { Toda esta alforja cargué } \\
\text { de firmas negadas. }\end{array}$ \\
\hline FÍLIDA & $\begin{array}{l}\text { Mira } \\
\text { que pesará la mentira } \\
\text { y vas caminando a pie. }\end{array}$ \\
\hline FABIO & $\begin{array}{l}\text { O que llevo de recetas, } \\
\text { que han aprovechado mal }\end{array}$ \\
\hline FÍLIDA & Tu llevas lindo caudal. \\
\hline FABIO & $\begin{array}{l}\text { Desto que escriben poetas } \\
\text { llevo un camello cargado; } \\
\text { pero porque tarde es ya } \\
\text { licencia y brazos me da }{ }^{9} \text {. }\end{array}$ \\
\hline
\end{tabular}

Y por último, para terminar con esta lista de axiomas sobre lo extendida que está la mentira en el mundo, no podía faltar el engaño de los engaños, «el amor, que también es mentira», por supuesto. En El villano en su rincón, Lisarda, la hija de Juan Labrador, intenta esquivar los envites de Otón, noble que acompaña al rey.

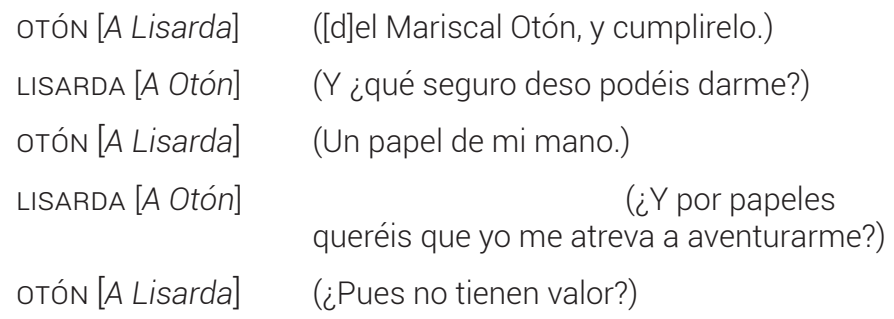

9. Lope de Vega, El marido más firme, vv. 2225-2251. 
LISARDA [A Otón]

(El que se mira

en las veletas que los aires mudan.

No hay verdad en amor, todo es mentira)..$^{10}$

Después de esta lista de mentiras traídas un poco a vuelapluma, se hace necesario poner un poco de orden y fijar el foco en aquellos casos en los que el engaño sustenta el desarrollo mismo de la comedia, en los que esta no funciona sin el concurso de aquel, pues es parte medular de la intriga dramática.

Ya me he referido antes a los trabajos de Roso Díaz, en los que este autor establece una tipología de los engaños que, si bien emanan del análisis de una selección del teatro lopesco, creo que serían fácilmente extrapolables a todo el teatro áureo en general, al menos a las comedias. Según esta los diferentes tipos de engaño que nos podemos encontrar serían:

1) Malentendidos (engañar con la verdad, el hablar equívoco, el engañarse, el engaño a los ojos).

2) Fingimientos y disimulos.

3) Identidades ocultas y mudanzas del ser (el ocultar la identidad; embozados y tapadas; el mudar de identidad).

4) Fingir enfermedades.

5) Engaños cuya base es un secreto.

6) Las verdades a medias.

7) El engaño infructuoso.

8) El engaño jocoso.

9) El engaño malicioso'1

Como el propio Roso admite, estos nueve modelos no sirven para establecer una tipología de comedias, sino que son elementos que, más concentrados o menos aparecen diseminados por múltiples comedias. Por tanto serían ser una herramienta que permitiría analizar la complejidad o profundidad de muchas de las tramas de nuestras comedias de enredo, por cuanto la acumulación de varios de estos criterios, redundará en una mayor importancia del engaño, como motivo general, en el desenvolvimiento de la trama.

Pues bien, siguiendo esta idea, mi intención ha sido, en la medida de lo posible, rastrear algunas comedias representativas, precisamente, de esta amalgama de engaños, comedias en las que, más allá de constituir un elemento importante, el engaño es la comedia y sin él, la comedia pierde sentido y, a veces, su razón de ser; y, más aún, intentar encontrar una conclusión plausible a la presencia de la mentira en las comedias. 
Un tipo de engaño que se presta muy bien a su mantenimiento como elemento estructural es la ocultación o el fingimiento de identidad y es de uso muy frecuente en nuestro teatro, con una recurrencia especial en la comedia palatina, género especialmente indicado para intrigas personales, anhelos no satisfechos o deseos de medrar que implican, a menudo, dar una visión de uno mismo alejada de la realidad. Tal y como defendió en su momento Joan Oleza, los episodios de suplantación están íntimamente relacionados con el género específico de la obra:

las comedias palatinas, cuyas coordenadas de espacio y de tiempo se establecen como imaginarias (lo sean o no lo sean), y a cuya acción se le permite la audacia de lo fantástico, tienen como núcleo central un episodio de ocultación de la propia identidad, bien por desconocimiento de la misma, bien por decisión estratégica: «Las comedias palatinas encuentran por tanto un eje temático importante en la problemática de la identidad, la máscara, el disfraz» ${ }^{12}$.

La propia estructura de la comedia, sus características más definitorias predisponen especialmente al fingimiento y a la ocultación. Las referencias de espacio, tiempo o límites sociales son a menudo imprecisos y el tono general suele disculpar acciones que en otros géneros serían censuradas.

Ejemplo palmario de lo anterior es la comedia El lacayo fingido, en cuyo inicio nos encontramos, en un tono bastante burlón, como la princesa Leonora se ha disfrazado de criado y pretende de tal guisa usar a un alcaide zafio y rústico al servicio de sus intereses. Al pobre alcaide le hace creer que su mujer, la del falso criado, ha dado a luz un pollino y le exige que ejerza su autoridad, prendiendo a la adúltera, como preámbulo del divorcio. Por si no fuera poco advierte al ingenuo de que la reina está enojadísima con él, por haber secuestrado y retenido a Rosarda en una torre por orden del rey.

El alcaide, asustado, corre a pedir perdón a la reina, que se entera en ese momento del secuestro, pues no sabía nada. Y esta era la verdadera intención de Sancho/Leonora, que la reina se enterase.

La tercera mentira, y mofa del alcaide, será hacerle aparecer en la corte desnudo, pretendiendo que va vestido con una milagrosa tela invisible (tema ya conocido en la cuentística tradicional desde tiempos remotos).

Todas estas mentiras están al servicio de la primera intención de Leonarda, conseguir al hombre que ama y vengarse de su infamador, el duque Rosimundo, que le había dado palabra falsa de matrimonio, otra mentira clásica del teatro áureo, que a la postre se tornará verdadera, pues se consuma el mismo gracias a las tretas de la dama disfrazada. Al mismo tiempo, la venganza también cae sobre el Rey, al que la disfrazada entorpece sus adúlteras intenciones con Rosarda.

No en pocas ocasiones esta suplantación de identidad lleva aparejado lo que podríamos denominar un cambio en el carácter, en la calidad del personaje. Me estoy refiriendo a las muchas ocasiones en que el protagonista se finge bobo, tonto

12. Oleza, 1995, p. 88

HIPOGRIFO, 3.1, 2015 (pp. 35-53) 
o loco, bien para escapar de una situación comprometida, bien para conseguir sus fines, de índole amorosa y/o de ascenso social. Es el caso de El bobo del colegio, Los locos de Valencia, La boba para los otros y discreta para sí, El cuerdo loco, El príncipe melancólico, El mármol de Felisardo, Los locos por el cielo y Los torneos de Aragón. En otras ocasiones los personajes se demuestran falsos bobos, sin que medie suplantación, sino por una suerte de mala interpretación de la propia personalidad o por la activación de un resorte escondido, el amor, que hace nacer la verdadera sagacidad, como ocurre con la Finea de La dama boba. Dentro del teatro un personaje como Finea parece distinguir entre tontos inconscientes y tontos suplantadores, a juzgar por sus palabras:

\begin{tabular}{|c|c|}
\hline FINEA & $\begin{array}{l}\text {... los que son tontos de veras, } \\
\text { ¿cómo viven? }\end{array}$ \\
\hline LAURENCIO & No sintiendo. \\
\hline PEDRO & $\begin{array}{l}\text { Pues si un tonto ver pudiera } \\
\text { su entendimiento a un espejo, } \\
\text { ¿no fuera huyendo de sí? } \\
\text { La razón de estar contentos } \\
\text { es aquella confianza } \\
\text { de tenerse por discretos } \\
\end{array}$ \\
\hline
\end{tabular}

Si bien el cambio de boba a lista de Finea se hará por el empuje de la fuerza amorosa, una vez tornada discreta, la dama no tendrá problemas para volver, fingidamente esta vez, a ser boba, ahora para esquivar las pretensiones de Liseo, de este modo da muestra paradójica tanto de su aprendizaje como de su recién adquirida sagacidad:

$\begin{array}{ll}\text { LAURENCIO } & \text { Pues, ¿sabrás fingirte boba? } \\ \text { FINEA } & \text { Sí, que lo fui mucho tiempo, } \\ & \text { y el lugar donde se nace lo saben los ciegos. } \\ & \text { Demás desto, las mujeres } \\ & \text { naturaleza tenemos } \\ & \text { tan pronta para fingir } \\ & \text { o con amor o con miedo, } \\ & \text { que, antes de nacer, fingimos }\end{array}$

Son varias las bobas, o bobos, que pueblan el teatro de Lope; boba es la Diana de La boba para los otros y discreta para sí, que pretende sus derechos sobre el ducado de Urbino con este mecanismo. Bobo es también el protagonista de la temprana El bobo del colegio, Garcerán, que llega a la ciudad de Salamanca en búsqueda de su amada Fulgencia, a la que ha conocido días antes en Valencia. La tradición del Colegio Viejo de acoger habitualmente a un simple da la idea al caballero de fingirse tal para, así, tener paso franco a diversos ámbitos, sociales y espaciales,

13. Lope de Vega, La dama boba, vv. 2619-2624.

14. Lope de Vega, La dama boba, vv. 2487-2495. Remito a los trabajos de Egido, 1978, y Ly, 1995, para un acercamiento más detallado al carácter de Finea. 
a los que de otro modo le sería difícil acceder, pues en su condición de bobo, tanto casas como grupos sociales son más abiertos y despreocupados de su presencia. Con el nombre de Pablos de Coria enreda y consigue la compañía de su amada, en una intriga de claras reminiscencias plautinas.

Hay un paso sutil, pero bastante significativo, que lleva de los bobos, fingidos o tornados discretos, a los locos. Como afirma José Enrique López Martínez mantienen concomitancias con los últimos, si bien su origen, literario al menos, es diferente.

Los bobos fingidos deberán la mayor parte de sus rasgos a los simples del teatro temprano del XVI, de la tradición entremesil y de la propia Comedia Nueva, ya en proceso de maduración. Son, pues, más literarios en rigor que los falsos locos, pero llegan a la escena una vez que estos han adquirido una cierta madurez teatral: son parte de la tradición de la locura fingida más que de la que proviene de los pastores simples ${ }^{15}$.

Los falsos locos también son numerosos en la dramaturgia del Fénix. A veces esta locura está falsamente inducida por un veneno, como ocurre con Blanca, en Lo que pasa en una tarde. Un falso veneno y una falsa locura sirven a la dama para organizar unas falsas bodas que a la postre resultan verdaderas. El engaño surte su efecto premiando al personaje ingenioso. Como puede verse una y otra vez en comedias de muy diversa índole, es frecuente que la mentira, si está movida por un fin respetable, el amor es el primero, pero también la recuperación de derechos de nacimiento, por ejemplo, no es castigada en el contexto de la comedia.

Victor Dixon ${ }^{16}$ afirmaba en su momento que la locura fingida es la metateatralidad más difícil de desarrollar en la comedia, pues no tiene el apoyo del traje. La propia dificultad del mecanismo parece que pudiera convertirse en un apoyo para el. Una suerte de metateatralidad a la inversa, en la que el personaje se ve favorecido por la pericia del actor, que interpreta, de hecho, no a uno, sino a dos personajes diferentes. A veces el mecanismo se complica aún más en manos del Fénix, uniendo en la comedia no a un loco fingido, sino a dos, como ocurre en Los locos de Valencia: la falsa locura del caballero Floriano, que usa el engaño para escapar de una acusación de asesinato, se une con la falsa locura de Eríila, tomada primero por loca por los demás para asumir luego voluntariamente su nueva condición. El premio para ambos será al final la consecución de sus deseos amorosos. En Los locos de Valencia es especialmente significativo cómo el engaño (en este caso el fingimiento de la locura) es intrínseco a la intriga, convirtiéndose no en un elemento más, sino en el elemento alrededor del cual gira todo, creándose un ingenioso entramado en el que los niveles de ficción y realidad se entremezclan de manera permanente. Esto permite al autor un uso muy productivo, en términos dramáticos, del recurso de «engañar con la verdad» especialmente querido por el Fénix. Dos locuras fingidas contiene también Los locos por el cielo, donde Dona e Indes huyen 
de la persecución de Maximiano contra los cristianos, aunque a la postre la treta no les libre del martirio ${ }^{17}$.

Como en el caso de los bobos, también los locos, mentirosos ellos, campan con notable éxito por las comedias de Lope, en El loco por fuerza Feliciano es ingresado en el Hospital de Locos de Zaragoza, como castigo por haber raptado a Clarinda. No está loco, si bien sufre un acceso de locura real al dudar del honor de su amada. Lo paradójico de esta comedia es que, si bien es obligado a entrar, estando cuerdo, en el hospital, será el fingimiento de la locura lo que le permita salir.

Los mismos fines, conseguir el amor, tienen otros falsos locos en comedias tempranas del Fénix, como El príncipe melancólico, donde el protagonista finge su locura ya que la dama a la que pretende ha decidido favorecer al infante, hermano del príncipe, o El mármol de Felisardo, donde el episodio de locura fingida, situado al final de la comedia permite al protagonista evitar una boda no deseada y burlar los deseos del rey para, una vez más, conseguir el matrimonio con la dama de la que está enamorado. No será loco fingido, sino loca, la protagonista de Los torneos de Aragón, Estela, que unirá al fingimiento el disfraz de varón. Ambos engaños, locura y condición masculina, le permiten huir de su potencial asesino, Arnaldo, y conseguir el favor real. En El cuerdo loco, por contra, encontramos de nuevo una asunción de la locura que podríamos calificar de sobrevenida. Rosania y el duque Dinardo planean envenenar al príncipe para apoderarse de su trono. Antonio, el príncipe, finge que el veneno ha hecho efecto y utiliza su fingida locura para protegerse a sí mismo y su reino. Hay en la comedia una suerte de doble fingimiento y las máscaras simbólicas son especialmente interesantes. Antonio es loco para Dinardo y Rosania, como lo es para el espectador; sin embargo para ellos la locura es real, mientras que para Antonio y el espectador esta locura es fingida. Esta fingida locura da lugar a enredos especialmente intrincados, con asesinatos fingidos que tapan otros reales. Todo al servicio del cuerdo loco que es Antonio y a la protección de su corona. Es reseñable cómo el proceso de locura fingida se constituye en una suerte de entrenamiento del monarca, de prueba de sus habilidades como regidor.

No son, por supuesto, los engaños de los bobos o locos fingidos los únicos que dominan la escena lopesca. Antes bien, este mecanismo del engaño se va complicando y los fingimientos son menos claros, menos evidentes, según avanza la maduración de la comedia. El recurso a la locura o la simpleza se va abandonando en favor de un mayor refinamiento en la construcción de los engaños. Prueba de ello es, por ejemplo, El perro del hortelano, donde se cumple la norma de que la localización, la categoría social y el tono frívolo, características propias de la comedia palaciega, coadyuvan a la anulación de un distanciamiento social y, a la postre, perdonan los excesos cometidos por Marcelo. No es el único caso en que se rompen las fronteras sociales, permitiéndose matrimonios desiguales que llegan después de un engaño prolongado. 
$\mathrm{Ni}$ el mecanismo del engaño es uniforme ni el género en que se inscribe tampoco, pues la mentira, como elemento intrínsecamente dramático, está presente a lo largo de toda la producción del Fénix. En una comedia como El caballero de Illescas encontramos de nuevo este mecanismo de engaño continuado de manera clara. Para Delia Gavela esta comedia marca la disolución del género picaresco y supone una amalgama de géneros entre los que se encuentran la comedia de capa y espada, la palatina o la tragicomedia del amor honor villano. Con estas premisas no es difícil suponer que el engaño, la suplantación y la mentira formarán parte indisoluble de su trama, como así resulta ser. La profesora Gavela, siguiendo a Oleza, ve en el protagonista de la obra, Juan de la Tierra, todos los pasos de la evolución del género picaresco: orígenes de truhán, carrera delictiva, triunfo fuera de España (Nápoles), caída y vuelta a los orígenes. En este caso, a diferencia de lo que ocurrirá con El perro del hortelano, por ejemplo, su mentira resultará verdad, porque su fingida identidad se demostrará, al final de la comedia, verdadera, integrándose en la tipología de comedias de identidad oculta ${ }^{18}$.

En El caballero de Illescas, el protagonista es ajeno a su condición real de noble, por tanto, la mentira urdida, aunque se torne verdad al final de la comedia, es consciente por parte de su urdidor, que en todo momento cree estar mintiendo al fingir una identidad ajena.

Suele ser común en este tipo de comedias que, de cara al espectador, el protagonista da muestras de su escondida nobleza: su personalidad oculta sobresale, sin pretenderlo siquiera, por encima del resto de los personajes y, por otro lado, suele ser habitual que estos nobles escondidos realicen algún tipo de hazaña magnífica que les reivindique finalmente y certifique su origen real, en este caso Juan salva la vida del futuro rey Fernando el Católico, sin saberlo. Son estas pistas que rompen la famosa cuarta pared, por cuanto en el escenario no parecen encaminar al resto de personajes hacia la escondida verdad, mientras que los espectadores, a buen seguro, podrían ir adelantándose, o al menos intuyendo, la resolución final y la restauración de identidades y estados.

Pese a todo, el protagonista de El caballero de Illescas no presenta ese comportamiento ejemplar a lo largo de toda la comedia. Antes bien, sus orígenes picarescos le llevan a comportamientos muy poco honrosos: robos, asesinatos, agresiones a damas y, lo que más nos importa aquí, la mentira sostenida no solo acerca de su identidad, sino en muchas otras cuestiones a lo largo de la comedia.

Esta cuestión sitúa al público, como al dramaturgo, en una situación un tanto complicada, por cuanto la resolución final de la comedia debe amortizar los muchos desvaríos que comete el personaje a lo largo de la obra.

El padre del personaje en cuestión, Juan Tomás, lo define de manera muy precisa con estas palabras:

Eres un Roberto, el Diablo,

no me obedeces, ni quieres,

18. Gavela, 2012. 


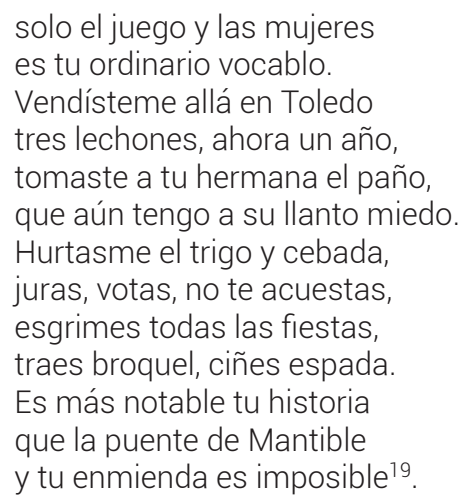

Y él asume desde bien pronto que va a jugar con su identidad frente a los demás

Dos hombres soy con dos nombres,

a quien dos mil tienen miedo,

y así por dos hombres puedo ${ }^{20}$.

En el segundo acto, después de haber cometido mil tropelías en su vida militar, huye a Italia y bajo el nombre de Juan de la Tierra, adopta esa nueva identidad que, al final de la obra, se tornará real, si no en el nombre, sí al menos en la condición.

Aún sin saberlo, el personaje de Juan reflexiona en varias ocasiones durante la comedia y justifica sus mentiras por el hecho de creerse capaz de acometer las empresas que serían dignas de un noble y no de un plebeyo como él.

En estas reflexiones siempre queda patente que, por encima de los muchos delitos cometidos, el más profundo, posiblemente, sea el de la mentira y el engaño sostenidos:

Subí, llegué, toqué. Cometa he sido,

solo me falta deshacerme luego.

Pero si estoy en la región del fuego,

¿que mucho que de allá salga encendido?

Tracé, dije, rendí, diose a partido

la gran ciudad, a cuyas puertas llego;

porque siendo español, parezco griego

en el engaño y el andar perdido.

Es fuerza, para aumento de sus glorias,

cebo dorado que las almas pescas,

la vela con que salen mis historias,

porque tendrán, si el viento me refrescas,

Toledo, fiestas y Madrid, vitorias,

laurel, amor y caballero, Illescas ${ }^{21}$. 
Paradójicamente, cuando Fernando el Católico restituya la condición de noble de Juan, lo único que quedará restaurado será el engaño, pues el resto de delitos, agresiones, asesinatos, etc., habrán sido reales y, a la postre, impunes.

Otro tipo de fingimiento de identidad es el que encontramos en ¿De cuándo acá nos vino?, una de las tradicionalmente denominadas de capa y espada, o urbana de enredo. En ella encontramos, como decía, un nuevo episodio de suplantación de personalidad, aunque con diferencias importantes respecto a la comedia anterior. En este caso la nueva identidad no se demuestra verdadera al final de la comedia, sino que se revela el engaño, si bien este no impide que el protagonista logre sus metas. A todo lo anterior hay que añadir que, pese a que con el transcurso de la comedia los objetivos del mentiroso, Leonardo, se irán tornando hacia lo amoroso, conseguir a la dama, en un primer momento sus intentos son meramente crematísticos, conseguir dinero y casa, pues han perdido el de la licencia jugando.

El alférez Leonardo se despide en Flandes del capitán Fajardo, después de haber cumplido sus obligaciones con el tercio. El capitán, dado que mantiene una relación estrecha con su alférez, le hace entrega de una cadena, para ayudarle con los gastos en la corte, y de una carga dirigida a su hermana, para que le ayude a su llegada. La urdimbre del engaño se produce en un lugar emblemático de Madrid y simbólico para las cuestiones de que tratamos, las gradas de San Felipe. Pocos lugares tan poco propicios para gestar una trama de engaños y simulaciones como las de ¿De cuándo acá nos vino? Sin entrar en profundidades de la trama solo diremos que, una vez perdido su dinero en el juego y, habiéndose encontrado en las gradas con Ángela, hija de la hermana del capitán, doña Bárbara, Leonardo decide manipular la carta de aquél y hacerse pasar por su hijo, habido con una dama flamenca, para conseguir dos cosas: el amparo y sostén de la casa de doña Bárbara y acceso a la dama, Ángela.

No contento con esto, según avanza la comedia, el alférez se enseñorea de la casa de la que es invitado y se aprovecha de su posición de hombre de la casa para espantar a los pretendientes de Ángela, para cortejarla y, simultáneamente, para jugar con los sentimientos de doña Bárbara, con la que flirteará hasta casi el final de la comedia.

En estas están cuando se anuncia la llegada del capitán Fajardo y Leonardo, por toda respuesta, huye de Madrid como alma que lleva el diablo. Pero es perseguido y alcanzado por el capitán que lo reta a un duelo. El alférez, sin embargo, logra ablandar al capitán, convenciéndole de que sus intenciones eran buenas y consigue que este le otorgue la mano de su sobrina, Ángela, con lo que el impostor ve premiadas sus mentiras con un buen casamiento y, de hecho, con una mejora notable de su situación económica.

Si atendemos a la clasificación, más detallada, de Delia Gavela vemos cómo varios de los componentes del género también coadyuvan a mantener la mentira como integrante fundamental del mismo:

- Tratamiento relajado del tema del honor, que favorece una restauración poco dolorosa. 
- Cierto carácter transgresor de damas y galanes, que añaden tolerancia a la ocultación, si los fines son amorosos o de ambición social.

- Juego dialéctico entre el honor (mayores, padres, hermanos) y placer (jóvenes galanes y damas), en la que los jóvenes suelen vencer una autoridad paterna desfasada.

- Ruptura de la verosimilitud por la sucesión de mentiras, fingimientos y ocultaciones.

- Tratamiento del decoro diferente del tradicional, causado por la extensión de las características cómicas a los personajes nobles.

- Obviamente el engaño y el doble juego entre personaje/personaje y personaje/ público.

- Protagonistas de baja nobleza urbana, más ridiculizables y con menos rigor en el tratamiento del honor.

- La ciudad como espacio, la economía escenográfica (juego calle/casa)

- Una onomástica reconocible completa esta lista de características.

Hay que decir, no obstante, que fiel a las condiciones de su género, el engaño está imbricado en toda la trama. No es únicamente el alférez el que miente: lo hacen doña Bárbara y Ángela, enfrentadas por el amor de Leonardo y, la segunda, deseosa de quitarse de encima pretendientes despreciables, lo hace Beltrán, compañero de Leonardo, para ayudar a su amigo e incluso el capitán Fajardo, una vez perdonado el alférez, accede a participar del engaño durante un tiempo antes de que se produzcan los emparejamientos definitivos del final de la comedia22.

Las mentiras en Lope, como en el teatro, son constantes a lo largo de toda su producción, si bien es cierto que los mecanismos concretos van variando con el tiempo. Los locos o bobos fingidos de su primera época son sustituidos por otros mecanismos, pero de manera general se mantiene la tendencia.

Responder a cuáles son las razones de esa presencia privilegiada del engaño, del fingimiento y de la mentira en el teatro lopesco es cuestión más compleja.

Hay mentira en el teatro porque el teatro es, en sí mismo, una mentira, y la mentira ofrece un innumerable abanico de posibilidades para armar la comedia, para organizar el enredo connatural a la misma. Pero existe, a mi juicio, una razón más de peso que explica esta presencia en nuestro teatro y que no tiene que ver con la configuración del hecho teatral en sí, sino con las características de la propia sociedad barroca. La mentira en el teatro es reflejo de una sociedad en que la mentira tiene un valor especial, al menos la preocupación por la mentira, exhibida de muchas maneras, y con muchas facetas diferentes, entre las cuales la preocupación por la apariencia y las disquisiciones acerca del ser y el parecer son moneda común de la sociedad de la época. El Barroco, de este modo, contiene el engaño como una de sus características definitorias. En este sentido llama poderosamen-

22. Gavela, 2005, pp. 304 y ss. 
te la atención el hecho de que el engaño rara vez es censurado o castigado en el contexto de la comedia. El decoro premia al sagaz, no necesariamente al que actúa de acuerdo a unos criterios éticos más o menos consensuados. También es cierto que, en ocasiones, estas victorias de los mentirosos, cuando no están animadas por un sentimiento legítimo, de recuperar el honor perdido, por ejemplo, suelen sufrir un cierto proceso de alejamiento temporal, espacial, una distancia artística que permite no pocas licencias que, de otra manera, no se podrían tolerar. La comedia es un ámbito que refleja partes de la realidad, que la recuerda y la remeda, pero no es la realidad, de ahí que no produzca conflicto ese premio continuo al engaño, ese representar continuamente tretas que dan lugar al triunfo de galanes, damas o criados mentirosos, con tal de que sus fines sean justificables. Y no es menos probable que también esas realidades que dibuja el teatro, identificables por el espectador, pero a suficiente distancia como para no verse demasiado condicionado por ellas, permitan una suerte de vía de escape, de posibilidad, por un lado, de soñar con un cambio social que en las comedias ocurre y, por otro, de constatar que las clases dirigentes son poseedoras de las mismas miserias morales que el resto de la sociedad.

Y una última reflexión: es innegable que una de las consecuencias más inmediatas, no solo de estos mecanismos, sino de la comedia en sí misma es la risa, mecanismo maravilloso que nos permite acercarnos con mucho más desparpajo a situaciones que serían difíciles sin su concurso y, por ello mismo, no exime de reflexiones profundas y nos da la distancia y perspectiva suficientes para mirar la realidad con otros ojos. El engaño, la mentira, el fingimiento nos hace reír, como el teatro.

\section{BIBLIOGRAFÍA}

Arellano, Ignacio, «El modelo temprano de la comedia urbana de Lope de Vega», en Lope de Vega: comedia urbana y comedia palatina. Actas de las XVIII Jornadas de Teatro Clásico (Almagro, julio de 1995), ed. Felipe B. Pedraza Jiménez y Rafael González Cañal, Almagro, Universidad de Castilla-La Mancha, 1996, pp. 37-59.

Carrascón, Guillermo, «Disfraz y técnica teatral en el primer Lope de Vega», Edad de Oro, 16, 1997, pp. 121-136.

Dixon, Victor, «Lo fingido verdadero y sus espectadores», Diablotexto, 4-5, 19971998, pp. 97-114.

Egido, Aurora, «La Universidad de Amor y La dama boba», Boletín de la Biblioteca de Menéndez Pelayo, 54, 1978, pp. 351-371.

García Lorenzo, Luciano, «Amor y locura fingida: Los locos de Valencia, de Lope de Vega», en El mundo del teatro español en su Siglo de Oro: ensayos dedicados a John E. Varey, ed. José M. a Ruano de la Haza, Ottawa, Dovehouse, 1989, pp. 213-228. 
Gavela García, Delia, «Perfilando géneros: algunas comedias urbanas del primer Lope», en Espacio, tiempo y género en la comedia española. Actas de las II Jornadas de Teatro Clásico, Toledo, 14, 15 y 16 de noviembre de 2003, ed. Felipe B. Pedraza Jiménez, Rafael González Cañal y Gemma Gómez Rubio, Almagro, Universidad de Castilla-La Mancha, 2005, pp. 303-317.

Gavela García, Delia, «Obras hacen linaje o la fuerza de la sangre: identidades fingidas en algunas comedias de Lope de Vega», en Máscaras y juegos de identidad en el teatro español del Siglo de Oro, ed. María Luisa Lobato, Madrid, Visor, 2011, pp. 217-234.

Gavela García, Delia, «Claves interpretativas de un texto lopesco: El caballero de Illescas», conferencia inédita impartida en el Coloquio Internacional Cincuentenario de la Asociación Internacional de Hispanistas, La Coruña, 12 de diciembre de 2012.

Hermenegildo, Alfredo, Juegos dramáticos de la locura festiva: pastores, simples, bobos y graciosos del teatro clásico español, Palma de Mallorca, Olañeta, 1995.

López Martínez, José Enrique, «Locos y bobos fingidos: otra forma de representar (sin disfraz) en el teatro de Lope de Vega», Atalanta. Revista de las letras barrocas, 2.1, 2014, pp. 53-96.

Ly, Nadine, «La Poética de la 'Bobería' en la comedia de Lope de Vega. Análisis de la literalidad de La dama boba», en La Comedia: Actas del seminario hispanofrancés (Madrid: 1991-1992), ed. Jean Canavaggio, Madrid, Casa de Velázquez, 1995, pp. 321-347.

Oleza, Joan, «La propuesta teatral del primer Lope de Vega», en Teatro y prácticas escénicas, II. La Comedia, dir. Joan Oleza, Londres, Támesis, 1986, pp. 251308.

Oleza, Joan, «Alternativas al gracioso: la dama donaire», Criticón, 60, 1994, pp. 3548.

Oleza, Joan, «Hagamos cosas de risa las cosas de calidad: El lacayo fingido, o las armas sutiles de la comedia», en La puesta en escena del teatro áureo, Cuadernos de Teatro Clásico, 8, Madrid, Ministerio de Cultura, 1995, pp. 85-119.

Oleza, Joan, «El primer Lope de Vega: un haz de diferencias», Ínsula, 658, 2001, pp. 12-14.

Oliva, César, «Corona y máscara en la comedia lopesca», en El teatro clásico español a través de sus monarcas, dir. Luciano García Lorenzo, Madrid, Fundamentos, 2006, pp. 45-64.

Roso Díaz, José, Tipología de engaños en la obra dramática de Lope de Vega, Cáceres, Universidad de Extremadura, 2002.

Roso Díaz, José, «El enredo de los locos en las comedias de Lope de Vega», en Locos, figurones y quijotes en el teatro de los Siglos de Oro. Actas selectas del 
XII Congreso de la Asociación Internacional de Teatro Español y Novohispano de los Siglos de Oro (Almagro, 15-17 de julio de 2005), coord. Germán Vega García-Luengos y Rafael González Cañal, Almagro, Universidad de Castilla-La Mancha, 2007, pp. 425-440.

Vega, Lope de, El anzuelo de Fenisa, ed. Luis Gómez Canseco, Alicante, Biblioteca Virtual Miguel de Cervantes, 2014.

Vega, Lope de, La boba para los otros y discreta para sí, Obras de Lope de Vega XI, Madrid, Atlas, 1929, pp. 472-507.

Vega, Lope de, El bobo del colegio, ed. Javier San José Lera, Salamanca, Universidad de Salamanca, 2001.

Vega, Lope de, El caballero de Illescas, Alicante, Biblioteca Virtual Miguel de Cervantes, 2002. Edición digital a partir de Parte catorze de las Comedias de Lope de Vega Carpio, Madrid, por Juan de la Cuesta, a costa de Miguel de Syles, 1620.

Vega, Lope de, El castigo sin venganza, ed. Alejandro García Reidy, Barcelona, Crítica, 2009.

Vega, Lope de, Las cuentas del Gran Capitán, Alicante, Biblioteca Virtual Miguel de Cervantes, 2005. Edición digital a partir de Parte veinte y tres de las Comedias de Lope Felix de Vega Carpio, Madrid, María de Quiñones, a costa de Pedro Coello, 1638.

Vega, Lope de, La dama boba, ed. Diego Marín, Madrid, Cátedra, 1994.

Vega, Lope de, ¿De cuándo acá nos vino?, ed. Delia Gavela García, Kassel, Edition Reichenberger, 2008.

Vega, Lope de, Del monte sale quien el monte quema, ed. Ana María Porteiro Chouciño, A Coruña, Universidad de La Coruña, Facultade Filoloxía, 2006.

Vega, Lope de, El laberinto de Creta, Alicante, Biblioteca Virtual Miguel de Cervantes, 1999. Edición digital a partir de: Menéndez Pelayo, Marcelino (ed.), Obras de Lope de Vega, XIV: comedias mitológicas y comedias históricas de asunto extranjero, Madrid, Atlas (BAE, CXC), 1966, pp. 51-98.

Vega, Lope de, El lacayo fingido, ed. Emilio Cotarelo y Mori, Obras de Lope de Vega Publicadas por la Real Academia Española (Nueva Edición), t. VII, Madrid, 1930, pp. 602-636.

Vega, Lope de, El loco por fuerza. Obras de Lope de Vega. Obras dramáticas II, ed. Emilio Cotarelo y Mori, Madrid, RAE, 1916, pp. 255-290.

Vega, Lope de, Los locos de Valencia, ed. Hélène Tropé, Madrid, Castalia, 2003.

Vega, Lope de, Los locos por el cielo, ed. Enric Bassegoda i Pineda, en Comedias de Lope de Vega. Parte VIII, Lleida, Milenio/Universitat Autónoma de Barcelona, vol. 1, pp. 305-427. 
Vega, Lope de, El marido más firme, Alicante, Biblioteca Virtual Miguel de Cervantes, 1999. Edición digital a partir de: Menéndez Pelayo, Marcelino (ed.), Obras de Lope de Vega, XIV: comedias mitológicas y comedias históricas de asunto extranjero, Madrid, Atlas (BAE, CXC), 1966, pp. 136-184.

Vega, Lope de, El mármol de Felisardo, ed. Beatriz Aguilar y Benet Marcos, en Parte VI de Comedias de Lope de Vega, Lérida, Milenio/Universitat Autònoma de Barcelona, 2003, III, pp. 1678-1680.

Vega, Lope de, Lo que pasa en una tarde, ed. Emilio Cotarelo y Mori en dsObras de Lope de Vega Publicadas por la Real Academia Española (Nueva Edición), t. II, Madrid, Tipografía de la «Revista de Archivos, Bibliotecas y Museos», 1916, pp. 291-325.

Vega, Lope de, Los torneos de Aragón, ed. Patrizia Campana y Jordi Pardo, en Parte IV de Comedias de Lope de Vega, Lérida, Milenio/Universitat Autònoma de Barcelona, 2002, II, pp. 726-728.

Vega, Lope de, El villano en su rincón, ed. Juan Antonio Martínez Berbel, Madrid, Castalia, 2010. 
